\title{
Literature Review: A Significant Feature of Writing a Research Report
}

\author{
Azizur Rahman, Mohd Zulkifle, Md Khursid Alam Ansari, Sidra, Mohammad Aslam
}

\begin{abstract}
Research is an objective-based, systemic, and rational approach to find the facts. The literature review plays a pivotal role in almost every operational steps of research. It clarifies the research field of the problem; provides the current state of knowledge, which guides the definite direction to study. It also points out the challenges, feasibilities, and suggests the best tools, technique, and methodology to achieve the objective of research. It does not only save time, money, and logistics of research but, also precise the study. Possible outcomes of the research could be predicted only after a proper literature review. The literature review must be concise, clear, critical, convincing, and contributive. There are six basic elements of the literature review i.e. information about data collector, the time frame of data collection, source of data, method and purpose of its collection, and its finding. There are three types of sources - primary, secondary, and conceptual/theoretical. Primary sources are unfiltered whereas secondary sources are filtered. A literature review minimizes the ambiguity of the study. Based on information collected through the literature review, the researcher becomes ready to deal with the difficulty and challenges of the study. The primary aim of this article was to provide information about the overall information of the topic. In this paper, significance and other characteristics of literature review are discussed.
\end{abstract}

Index Terms - Literature review, Research, sources, steps, feature.

\section{INTRODUCTION}

The term 'Research' is defined as the collection of data that helps to answer the questions on various aspects and of interests in the particular discipline [1]. Research is a way of scientific and inductive thinking [2],[3], examining critically the various aspects of daily professional work; proper understanding, and generating guiding principles that govern a particular procedure. And also research develops new theories that contribute to the advancement in practice and professions [3]. Rao (2010) defined the research as 'it is the search for new knowledge systematically and scientifically' [4]. The literature review signifies the most important step of the research process in all types of research studies. It is a written document of logically argued and comprehensive information about a topic of study [5]. The literature review is a fundamental part of the research course that plays an important role in almost every operational phase [3].

Azizur Rahman, Lecturer, Dept. of Mahiyatul Amraz (pathology), NIUM, Bangalore, India

Mohd Zulkifle, Professor, Dept. of Kulliyate Tib (basic concepts), NIUM, Bangalore, India

Md Khursid Alam Ansari, PG Scholar, Dept. of Mahiyatul Amraz (pathology), NIUM, Bangalore, India

Sidra, PG Scholar, Dept. of Mahiyatul Amraz (pathology), NIUM, Bangalore, India

Mohammad Aslam, Department of Preventive and Social Medicine, AMU, Aligarh, India
McEvoy et al. (2009) highlighted the significance of literature review as: "A literature review is a scholarly paper that presents a logically argued case founded on a comprehensive understanding of the current state of knowledge about a topic of study. It is a written report that chronicles and makes the case for the results of your research of the literature on the study question posed" [6]. Additionally, Onwuegbuzie et al. (2010) provide a broader definition, by stating that the literature could represent any of the following sources: "research articles, opinion articles, essays, review article, monographs, dissertations, books, Internet websites, video, interview transcripts, encyclopedias, company reports, trade catalogs, government documents, congressional/parliamentary bills, popular magazines, and advertisements" [5]. A literature review pursues to describe, summarise, evaluate, clarify, and/or integrate the content of primary and secondary data [7]. By understanding how to review the literature, the researcher will be able to utilize the resources of the library [4].

\section{THE GOAL OF A LITERATURE REVIEW}

The review of the literature aims to obtain an apt understanding of the previous relevant research and to explain that information in the written report form [8]. It provides a base of knowledge on a particular research topic. (Figure 1) Other aims of the review of literature are as follows:

- Point out the gaps in previous research and conflicts.

- Justify the research.

- Place the research work within the context of existing literature and states the need for further study.

- Identify the major informative works in the field by other researchers.

- Ascertain renowned researchers working on this topic.

- Indicate the novel ideas, conclusions, and theories.

- Make the researcher able to find out the similarities and differences.

- Detect main research methodologies and techniques.

- Demonstrate relationships between previous studies or theories [9].

- Provide a framework for research.

- Explore existing information in the fields of research.

- Discover research strategies.

- Find out specific data collection approach that has or has not been productive in investigations of topics similar to yours.

- Help researchers to avoid mistakes done by other researchers.

- Suggest new ideas and procedures that researchers previously had not considered [10]. 

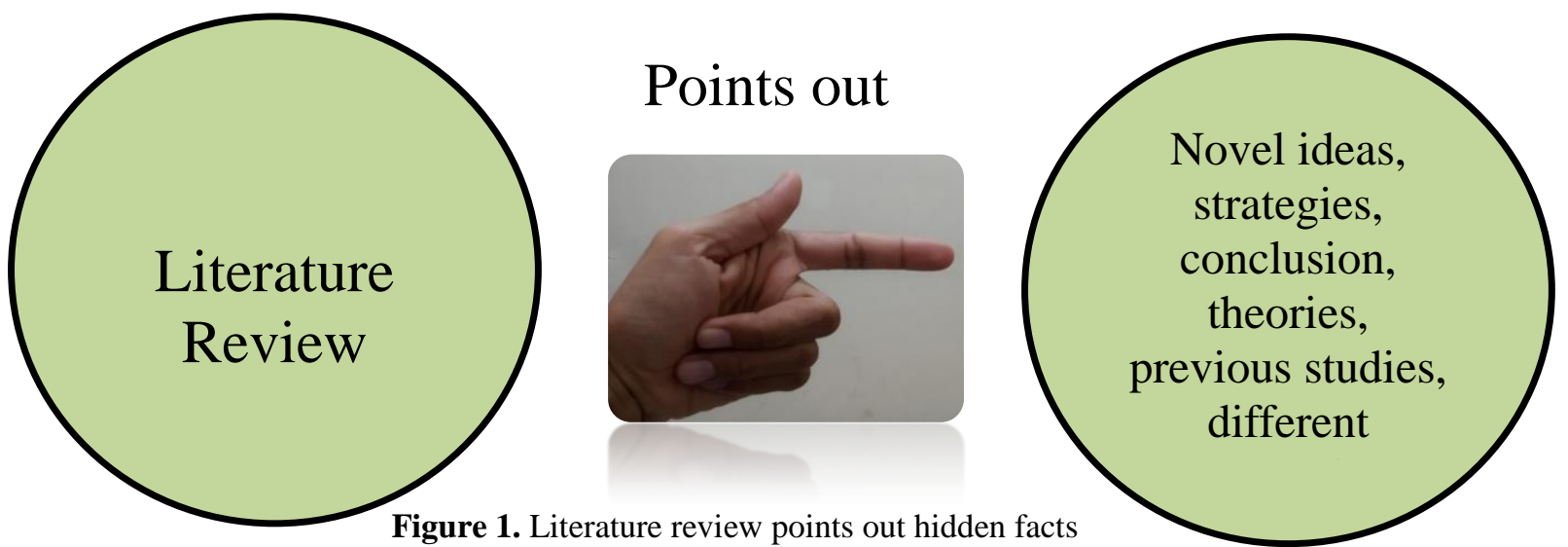

\section{FOREDEALS OF LITERATURE REVIEW}

Literature Review is beneficial for the author by providing an in-depth understanding and knowledge of their concerned subject. It provides the proper setting of the research. It renders the scientific plan of the manuscript to scrutinize the research result. It guides how knowledge has changed within the research subject. Gives an idea of how much works has already been done on a particular topic. It provides information on the generally accepted facts, emerging and current state of the research topic. Review of Literature points out the research gap that is still unknown or not points out
Table 1 recognized. It expresses how the research fits within a larger field of study. It gives an outline of the sources searched during the study of a particular topic [11].

\section{PHYSIOGNOMIES OF LITERATURE REVIEW}

The general appearance of the Literature Review must include the five 'Cs' (Concise, Clear, Critical, Convincing, and Contributive) to make the literature review appealing (see Table 1)[12],[13],[14]. Additionally, Steward said, a good review should be comprehensive and analytical [15],[16].

\begin{tabular}{|c|c|c|}
\hline $\begin{array}{l}\text { S. } \\
\text { No }\end{array}$ & Five Cs & Description \\
\hline 1. & Concise & $\begin{array}{l}\text { A review of literature should be a concise synthesis of a broad collection of literature on a } \\
\text { given subject. }\end{array}$ \\
\hline 2. & Clear & $\begin{array}{l}\text { Processes of data collection must be clear that form the foundation of the literature review } \\
\text { is important for a rigorous review; and, frequently, submitted manuscripts fail to } \\
\text { communicate the procedures used in conducting the literature review. }\end{array}$ \\
\hline 3. & Critical & Rigorous literature reviews comprise of both critical reflection and evaluative analysis. \\
\hline 4. & Convincing & Literature must be in a convincing pattern. \\
\hline 5. & Contributive & $\begin{array}{l}\text { The most important characteristic of the literature review is that must contribute to the } \\
\text { concerned topic like other researches. }\end{array}$ \\
\hline
\end{tabular}

which did you remove?

\section{ELEMENTS OF A LITERATURE REVIEW}

There are six basic elements (Who, When, Where, How, What, Why) are usually included during literature review:

- Who has collected the literature as "data?" like one or all authors, assistants or research teams, etc.

- When were the data collected, during a particular time frame? Or the time frame for data production was not specified?

- Where were the data collected? Did the researcher use only academic journals? Or collected from books, or even trade publications and web pages or any other source?

- How were the data established? Did you search the archives (if yes, which word and what keywords were used)? Has the researcher used personal networks to find the publications? Did you select the escalate (snowball) process? Did you collect the data through potentially relevant manuscripts to see the unforeseen findings?

- What were the findings? How many artifacts that formed the research recordset? Which record did you retain, and
- Why did the researcher select the data that were included in the final data set? Mention the criteria of selection [12].

\section{ESSENTIAL CLASSIFICATION OF LITERATURE REVIEW}

Classification of the literature review is beneficial in the selection of the review process and it help to find out the criteria of research methodology.

1. Simple - In a simple literature review, there is a briefing of the subject not necessarily purely academic in scope and often uses only popular sources. This type of review is done mostly as the start of the research procedure.

2. Applied-This type of review is used mostly in business, government, and other professional environments to find out more facts and to eliminate the inadequacies. It is done to know the marketability and profitability as well as the change and value objectivity and accuracy in similar tasks and programs.

3. Academic - It requires accuracy, quality of sources, the 
objective of research, thoroughness, and proper analysis. Academic Review requires seriousness and concentration during the review. It includes a summary and synthesis of sources usually within a given conceptual framework [9]. Some other forms of literature review include the integrative [14], the historic [17], and the rapid structured literature review [18].

\section{STEPS IN LITERATURE REVIEW}

By following the important steps, the researcher can reach to novel ideas and findings of the literature. (Figure 2)

Define research question
Confirm the relevant primary and secondary sources

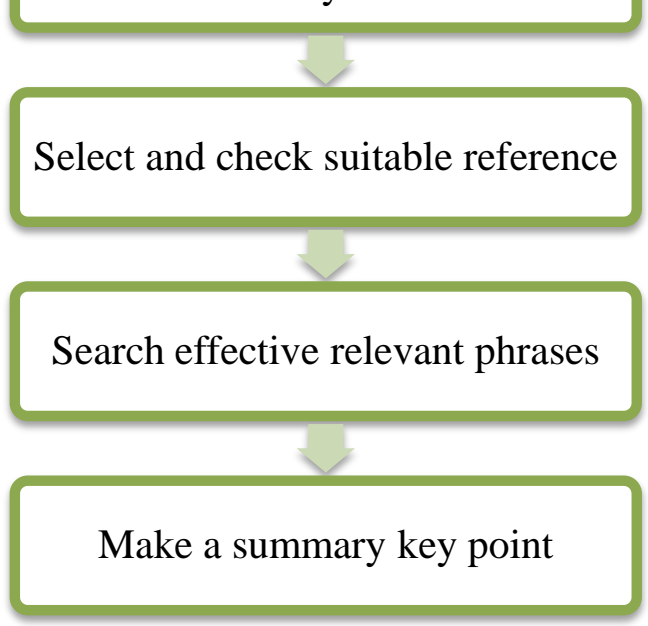

Figure 2. Steps of Review

1. First of all, researcher must define the research question as specifically as possible. 2. Look and confirm the relevant secondary sources. 3. Select and check one or two suitable reference works. 4. Articulate search keywords or phrases relevant to the research problem or question of interest. 5. A researcher should search the general references for relevant primary data sources. 6. Obtain, read, and note relevant from available sources [5]. primary sources properly, and make a summary key point

Table 2

\begin{tabular}{|c|c|c|}
\hline S. No & Type of source & Example \\
\hline 1. & Primary (unfiltered sources) & $\begin{array}{l}\text { Letters/correspondence, diaries, autobiographies, official or research } \\
\text { reports, patents and designs, and empirical research articles, works of art and } \\
\text { literature, speeches and oral histories, audio and video recordings, } \\
\text { photographs and posters, newspaper ads and stories, laws and legislative } \\
\text { hearings, census or demographic records, plant and animal specimens, coins } \\
\text { and tools. Unpublished manuscripts, Statistical and survey data and } \\
\text { Interviews. }\end{array}$ \\
\hline 2. & Secondary (filtered sources) & $\begin{array}{l}\text { Review articles, academic journal articles (other than empirical research } \\
\text { articles or reports), seminar chronicles, books (monographs or chapters of a } \\
\text { book), documentaries, dictionaries, and encyclopedias, Magazine, Library } \\
\text { Catalogue, Historical Abstracts, Computer-based literature search } \\
\text { MEDLINE, MEDLARS, CATLINES, The Index Medicus, and International } \\
\text { Nursing Index, etc. }\end{array}$ \\
\hline 3. & Conceptual/theoretical & $\begin{array}{l}\text { Papers concerned with description or analysis of theories or concepts } \\
\text { related to the topic available on website or in journal hard copy etc. }\end{array}$ \\
\hline
\end{tabular}

IX. EVALUATING THE SOURCES

At the time of evaluation of literature sources, it is important to distinguish which data can be regarded as reasonable or beneficial to research question [22]. The sources must have potentiality e.g. scholarly empirical

Sources must be reliable, valid, authentic, and very much related to the research problem. (Table 2) [2],[4],[19],[20],[21]. 
articles, dissertations, and books [23],[24]. The appearance of a literature review should not be just as a summary of the source. Collected literature should be compared each source to other relevant literature on the same research problem. A researcher must critically evaluate each source. During the evaluation of the literature, a researcher should indicate how each source is contributing to the main text of the topic. Additionally, integrate the discussion of the data sources to the relevant argument about the state of information on the research topic [8].

\section{USES OF LITERATURE REVIEW IN RESEARCH}

The use of a literature review in scientific documents can be summarized into an analytical approach to enable the multifold scope of its understanding. It enables the researcher to interpret the existing literature in light of updated information in the particular field to establish the reliability in knowledge and relevancy of existing data. Other uses are as:

1. A literature review calculates the impact of the latest facts easily in the subject area by plotting the progress of information.

2. It finds out the contradictions between different thoughts within the research area to establish facts.

3. It indicates the current research place in the representation of a specific field.

4. It makes available information for relevancy and coherency to check the direction of the research process.

5. It aids as a starting point of any upcoming research.

6. It justifies the study and sets up the research problem.

7. Provides a theoretical framework including the concepts and theories of the research.

8. It guides to adopt a more suitable research methodology by probing the strengths and weaknesses of current research in the same field [11],[25].

9. Uplifts the connotation of the results by comparing it with the present literature

10. It provides relevant reference sources that could increase more of its reliability with the readers.

11. Prevents plagiarism and saves the scientific article from rejection and thus also minimizes the expenditure of time and money.

12. It supports assessing, condense, and synthesizing ideas in the author's own words to improve the research focus.

13. Helps to show the originality and uniqueness of the research work.

14. Justifies the essentiality of conducting the specific research in a particular field.

15. Points out the knowledge gaps of the researcher.

16. Review of literature helps the readers to find the unsolved problems and issues, the emerging styles, and approaches.

17. A deep review of many relevant bibliographic sources will enhance the chances of publication in reputed scientific journals [11].

18. During the review, a researcher learns about significant ideas, research methods, and experimental procedures that are used in the related field [8].

19. Explains the underlying expectations (suggestions) behind the research problems that are central to the research proposal [10].

20. Defines the limitations of the research
21. Identifies areas that need further research [1],[8].

22. It makes the data more accessible and convenient to publication of research [26],[27].

\section{CONCLUSION}

A literature review is as important as any other section of the research process and can be conducted quite painlessly if approached in an orderly manner. After rigorous review, it was found that the experts have outlined the best steps and characteristics of literature review; a researcher should follow these steps to conduct a flawless literature review to gain more trust from readers and have the chance of seeing the work accepted by reputed journals, written in classical books, and developed by other agencies.

This writing aimed to collect some of the key features of literature review to provide an accessible source of knowledge for researchers seeking to write literature reviews.

\section{ACKNOWLEDGEMENT}

All contributors are highly thankful for their contributions.

\section{CONFLICT OF INTEREST}

Authors have no conflict of interest.

\section{REFERENCES}

[1] Anonymous, "Chapter: 2 Review of Literature \& Research Methodology." file:///H:/Review/chapter 2, Web Page.pdf (accessed Jul. 20, 2020).

[2] C. Kothari and G. Garg, Research Methodoly, Methods and Techniques, 3rd ed. New Delhi: New Age International Publishers, 2014.

[3] R. Kumar, Research Methodology, 3rd ed. New Delhi: SAGE Publications India Pvt Ltd, 2011.

[4] T. B. Rao, Research Methodoly, 3rd ed. New Delhi: Paras Medical Publisher, 2010.

[5] A. J. Onwuegbuzie, N. Leech, and K. M. Collins, "Qualitative Analysis Techniques for the Review of the Literature," Qual. Rep., vol. 17, no. 56, pp. 1-28, 2012.

[6] B. T. McEvoy and L. A. Machi, The Literature Review: Six Steps to Success. California: Corwin Press, 2009.

[7] H. Cooper, Integrating research: a guide for literature reviews, 2nd ed. Newbury Park, California: Sage Publications, 1989.

[8] Anonymous, "Literature review purpose," West. Sydney Univ. Libr., pp. 2017, [Online]. Available: https://www.westernsydney.edu.au/_data/assets/pdf_file/0006/12547 86/Literature_review_purpose.pdf.

[9] Anonymous, "Literature Review: Purpose of a Literature Review," 2020. https://uscupstate.libguides.com/c.php?g=627058\&p=4389968 (accessed Jul. 23, 2020).

[10] L. R. Gay, G. E. Mills, and P. . Airasian, Educational Research: Competencies for analysis and applications, 8th ed. Upper Saddle River, NJ: Merrill Prentice Hall, 2006.

[11] Anonymous, "Why is it important to do a literature review in research?"" 2019 https://pubrica.com/academy/2019/08/08/why-is-it-important-to-do-aliterature-review-in-research/ (accessed Jul. 23, 2020).

[12] J. L. Callahan, "Writing Literature Reviews: A Reprise and Updat," Hum. Resour. Dev. Rev., vol. 13, no. 3, pp. 271-275, 2014.

[13] D. Denyer and C. Pilbeam, "Doing a literature review in business and management," 2013.

[14] R. J. Torraco, "Writing integrative literature reviews: Guidelines and examples," Hum. Resour. Dev. Rev., vol. 4, pp. 356-367, 2005.

[15] A. Bolderston, "Writing an Effective Literature Review," J. Med. Imaging Radiat. Sci., vol. 39, pp. 86-92, 2008, doi 10.1016/j.jmir.2008.04.009.

[16] B. Steward, "Writing a literature review," Br J Occup Ther, vol. 67, pp. 495-500, 2004.

[17] J. L. Callahan, "Constructing a manuscript: Distinguishing integrative literature reviews and conceptual and theory articles," Hum. Resour. Dev. Rev., vol. 9, pp. 300-304, 2010. 
[18] A. Armitage and D. Keeble-Allen, "Undertaking a structured literature review or structuring a literature review: Tales from the field," Electron. J. Bus. Res. Methods, vol. 6, pp. 103-114, 2008.

[19] J. Graf, Identifying Primary and Secondary Sources. Bloomington: IU Libraries, Indiana University.

[20] Anonymous, "Primary and Secondary Sources," Bowdoin College Library.

https://library.bowdoin.edu/research/primary-and-secondary-sources.s html (accessed Jul. 19, 2020).

[21] [21] P. K. Oberoi, Research Methodology. New Delhi: Global Vision Publishing House, 2015.

[22] J. Meltzoff, “Critical Thinking About Research,” JEPS Bulletin, 2007. https://blog.efpsa.org/2011/08/01/how-to-critically-evaluate-the-qualit y-of-a-research-article/ (accessed Jul. 24, 2020).

[23] A. S. Denney and R. Tewksbury, "How to Write a Literature Review," J. Crim. Justice Educ., pp. 1-17, 2012, doi: 10.1080/10511253.2012.730617.

[24] B. L. Berg, Qualitative research methods for the social sciences, 7th ed. Boston: MA: Allyn \& Bacon, 2009.

[25] Anonymous, "Conducting a Literature Review- Chapter 3," SAGE publications, 2019. https://us.sagepub.com/sites/default/files/upm-assets/90135_book_ite m_90135.pdf (accessed Jul. 24, 2020).

[26] M. Grant and A. Booth, "A typology of reviews: an analysis of 14 review types and associated methodologies," Heal. Inf Libr J, vol. 26, no. 2, pp. 91-108, 2009.

[27] A. Rahman, M. Zulkifle, M. Aslam, and M. R. Khan, "Components of Writing a Review Article," J. Integr. Community Heal., vol. 8, no. 1, pp. 8-12, 2019, doi: 10.24321/2319.9113.201902. 